\title{
Descobrindo Percursos para a Pesquisa em Saúde no Trato com o Movimento Social ${ }^{1}$
}

\section{Discovering Pathways for Health Research in Dealing with the Social Movement}

\author{
Elizabeth de L. M. Smeke ${ }^{2}$
}

\section{SM EKE, E. L. M . D iscovering Pathways for H ealth R esearch in D ealing with the Social}

M ovement. Cad. Saúde Públ., Rio de Janeiro, 9 (1): 39-47, jan/mar, 1993.

This article is about methodology for scientific research in health, where the researcher is an important part of the object of investigation.

The implementation of a broad-based Health Reform in B razil depends on the involvement of users. It is important to guarantee these social rights. Many experiences sharing this concern are going on in this country. Still, research on the relationship between institutional work in health and the Social Movement lacks a predefined methodology.

Therefore, the main objectives of this study are the following: to contribute to the discussion of possible ways of approaching the mechanisms of relationships between health and users of health services, and to collaborate with the development of the citizenship process.

This work was done through theoretical research on participatory methodology and "actionbased research". The following aspects are particularly important: definition of the object of study, self-positioning by the researcher, subjective explanations, documentary surveys and interviews for case studies, and feedback to theory.

Finally, the author concludes that this methodology allows for an understanding of some mechanisms that explain the relationship between macro- and micro-structural analyses. In addition, one also observes a maturation process in the research protagonists.

Keywords: Health Education; Popular Participation in Health; Social Movement \& Health; Social Research in Health

\section{INTRODUÇÃO}

A questão do avanço, do aprofundamento e do amadurecimento de um projeto de reforma sanitária no Brasil passa, inevitavelmente, pela articulação entre as propostas, as práticas e seus agentes e a clientela, organizada ou não.

As poucas, mas importantes, conquistas no plano institucional, acrescidas da experiência

\footnotetext{
${ }^{1}$ Pesquisa realizada com apoio financeiro da Financiadora de Estudos e Projetos (FINEP) e da Pontifícia Universidade Católica de Campinas (PUCCAMP).

${ }^{2}$ Departamento de Medicina Social e Preventiva da Faculdade de Ciências Médicas da Pontifícia

Universidade Católica de Campinas, Campus II. Av. John Boyd Dunlop, s/n, 13033-780, Campinas, SP, Brasil.
}

concreta que muitas prefeituras oposicionistas puderam experimentar a partir do final dos anos 70 , bem como de experiências que ainda se desenvolvem nos "interiores" desses "Brasis", revelam a importância da articulação entre agentes da Reforma Sanitária, no plano institucional, e a população, através de programas, serviços, etc.

No entanto, a multiplicidade dessas experiências necessita ser contada para que estas sejam refletidas, avaliadas e recriadas, para crescer e encontrar seus parceiros e interlocutores, nem sempre próximos no cotidiano.

Um dos problemas com os quais nos defrontamos nessa tarefa é o rigor científico que nos permita a consciência da paixão e do desejo, sem perder o pé crítico da realidade. 
Entretanto, o percurso nem sempre é simples. E não está dado, como para outros objetos do conhecimento.

Assim, este trabalho pretende contribuir para uma discussão metodológica para a descrição e análise de experiências que tratem de questões decorrentes da articulação entre projetos e propostas de atenção à saúde e movimentos ou grupos organizados de usuários.

O que se segue é um pouco do percurso que adotei ao estudar as relações entre a Secretaria Municipal de Saúde de Campinas e o movimento popular da época, autodenominado Assembléia do Povo, entre 1977 e 1981, tendo participado no processo (Smeke, 1989).

Tenho a intenção de que, submetendo-o à apreciação crítica de outros pesquisadores, este trabalho possa apontar percursos e ferramentas que possam servir de instrumentos que tornem mais rápidos, críticos e numerosos os caminhos analíticos de experiências desta natureza, ampliando o seu debate.

\section{AS DIFICULDADES IMPOSTAS PELO TEMA}

Investigar questões que tratam do Movimento Social já é, em si, uma árdua tarefa, sobretudo quando se quer articulá-las à saúde. A sua característica mais tradicional é ser uma prática social controladora e normatizadora que, do ponto de vista político, realiza-se em função da manutenção das relações de poder e recriação das relações de dominação, especialmente através de suas ações institucionalizadas.

O problema torna-se um pouco mais difícil quando se quer analisar tal relação através de práticas em saúde que pretendam romper com essa perspectiva de ação tradicional e, ainda mais, quando o tema se abre para um campo de conhecimento cuja juventude não garante nem sugere, a priori, nenhum percurso.

Em geral, esta situação é acrescida de dificuldades mais visíveis, como a escassa documentação de alguns momentos, a dificuldade de encontro com os agentes, o seu estado emocional, o excesso de ativismo, o compromisso com variadas tendências político-partidárias, bem como a apontada deficiência de uma metodologia predefinida em pesquisa nesta área. Tudo isto coloca limites, ao mesmo tempo que aumenta as exigências para uma avaliação mais precisa desse processo, que, em última análise, é político.

Deve tratar se de uma reflexão cuidadosa, especialmente se o trabalho não pretende "sobrevoar o real", olhá-lo de fora como um observador privilegiado numa distante tribuna, mas por dentro de seu processo interno, tomando partido manifestamente, uma vez que os resultados deverão servir para novas interações.

A opção, para início, pelo estudo de caso como método adequado à descrição cronológica pretendida permite, no meu entender, uma abordagem mais facilmente compreensível, no sentido de evitar a perda de detalhes importantes que, de outra forma, poderiam passar despercebidos. Este caminho também deixa transparecer mais claramente determinadas subjetividades decorrentes da participação na experiência em estudo e, assim, possibilita uma reflexão mais profunda, fazendo redobrar os esforços por uma coleta de dados mais ampla. Desta forma, podem ser favorecidas interpretações cuja inevitável parcialidade encontre eco nos acontecimentos documentados, e não nas fantasias ou idealizações, comprometendo-se com a clareza e a racionalidade. Com possíveis generalizações, corre-se o risco de perder o valor do específico, da experiência concreta, levando a abstrações inadequadas, a partir de valores preconcebidos. A riqueza do concreto parece mais recuperável a partir da descrição de eventos dentro do caso, considerados importantes, de alguma forma marcadores das preocupações mais relevantes.

No caso da investigação referida, buscavam-se marcadores que apontassem para a contribuição ao avanço das práticas e atuações em saúde ocupadas em favorecer, ou ao menos não atrapalhar, o processo de organização popular no rumo de sua emancipação. E, assim, foram escolhidos momentos, no período estudado, onde as relações pareciam mais evidentes.

Mas como? Quais procedimentos? Quais instrumentos mais adequados e "cientificamente" válidos?

De imediato, a intuição aponta para a necessidade da combinação de várias técnicas para a reconstituição histórica. No caso, foi recolhida toda a documentação produzida: panfletos, 
cadernos e fotografias, resumos de atas de reuniões, etc. Foram feitas pesquisas em jornais oficiais e tablóides, bem como entrevistas abertas com narrativa livre e depoimentos dos agentes envolvidos no processo (Aguiar, 1978). Dentre estes encontravam-se representantes de vários setores da igreja católica, agentes pastorais, médicos integrantes da experiência, mais articulados à Assembléia do Povo e à implantação do projeto, além de outros ligados às várias tendências políticas, também participantes da experiência, auxiliares de saúde, o secretário municipal de saúde da época, entre outros. Da mesma forma, foi utilizada a experiência advinda da minha participação.

A utilização destes recursos não é comum na área das ciências médicas e biológicas. São, na verdade, os instrumentos de trabalho mais tradicionais das ciências sociais, entendidas como ciências do Homem (Asti Vera, 1974), cuja contribuição para a construção do campo de conhecimento da saúde coletiva tem sido de grande valor.

Contudo, o percurso metodológico depende da abordagem teórica, onde devem encontrar eco os conteúdos do estudo e suas proposições, apesar de que

"não existem ciências por excelência, não existe um método por excelência, um 'método em si'. Cada investigação científica deve criar um método adequado, uma lógica própria cuja generalidade ou universalidade deve consistir em ser 'conforme com o objetivo'" (Gramsci, 1977).

\section{O CASO NO CAMPO DAS RELAÇÕES E DO CONFLITO}

Como já foi mencionado, este tipo de trabalho propõe-se a registrar ou reconstituir uma dada situação, questionando, através dos dados obtidos, o envolvimento da medicina - enquanto atividade que se viabiliza através da política de saúde - com o social que se institui, e destacando, portanto, as práticas e mediações entre o Estado e a Sociedade através de uma dada técnica. Em outras palavras, entendendo o Estado como uma condensação da correlação de forças sociais nacionais e internacionais, politicamente organizadas, onde se articula toda uma importante fração tecnoburocrática (Poulantzas, 1977, 1978, 1985; Cardoso \& Faletto, 1973); entendendo a política social como um campo de práticas onde se revelam os interesses deste Estado em legitimar-se junto aos diversos setores sociais que circunstancialmente exerçam maior ou menor pressão, especialmente com referência às imposições realizadas pela fração tecnoburocrática (Teixeira, 1986; Andrade, 1980; Offe, 1984; Hirsh, 1977); considerando as organizações populares como expressões organizativas das categorias excluídas em busca de posição, segundo um mecanismo de construção democrática (Jacobi \& Nunes, 1982; Doimo, 1981; Boschi, 1982); pretendendo questionar as práticas e apontar perspectivas de atuação técnica que possam ser buscadas no interior desta política social, no caso a saúde, no sentido de contribuir para um processo de emancipação social.

Pode-se considerar, portanto, que se trata de uma tarefa cujo campo de análise deve estar no realizar-se do social, em constante movimento de instituição. Um campo que intercepta as relações conflitivas entre o indivíduo, enquanto categoria de apelo ideológico; o coletivo, enquanto objeto mutante da política social; o social, enquanto conformação em movimento; e o político, enquanto jogo de forças capaz de estabelecer transformação. É uma tarefa que parece efetivamente operar no registro analítico preponderantemente superestrutural, enquanto relações que se dão entre o campo simbólico da representação do poder e o imaginário, representado por esperadas práticas estatais, no interior da sociedade civil. Em uma perspectiva onde a consciência da estrutura, por parte do sujeito histórico, é que gera o movimento da superestrutura capaz de tornar a "estrutura de subordinante a subordinada" (Bobbio, 1982) e onde o imaginário, como salienta Chauí (1981), não se coloca como algo fantástico e irreal, “...mas no sentido de conjunto coerente e sistemático de imagens e representações tidas como capazes de explicar e justificar a realidade concreta" (pg. 19), no caso, a representação que as organizações e o Movimento Popular possam ter a respeito do Estado.

Assim, por tratar-se da análise de uma relação onde está presente o conflito, o confronto, o dinâmico, segundo vários autores e a própria 
experiência apontam, vários enfoques teórico-metodológicos têm realmente de ser abandonados. Tanto o chamado empiricismo positivo como também o funcional não são úteis (Mills, 1965; Thiollent, 1981).

Fernandes (1947), em uma discussão entre a adequação dos diversos referenciais teóricos em sociologia, já afirmava: "Para pesquisar a estabilidade - o método positivo (...), para pesquisar o conflito, o mutável - 0 método histórico" (pg. 341), apontando, na mesma obra, a inviabilidade da sociologia positiva que "tende a colocar o sujeito diante da realidade social, como se fosse possível uma barreira entre ambos" (pg. 340).

Mills (1965) concorda com ele, levando o confronto para a teoria funcionalista de Talcott Parsons, onde "Não há lugar para o (estudo do) Movimento Social, para as revoltas e revoluções" (pg. 41), quando critica, contundentemente a "Grande Teoria" (The Social System), para este tipo de objeto, porque nela

"A causa básica (...) é a escolha inicial de um nível de raciocínio tão geral que seus praticantes não podem, logicamente, descer até a observação. Jamais, como grandes teóricos, abandonam as altas generalidades para se ocuparem dos problemas em seus contextos histórico e estrutural" (pg. 41).

\section{LIVRE DO ESPECTRO DA EXIGIDA NEUTRALIDADE}

Portanto, é assim que autores de várias correntes, estudiosos da metodologia sociológica, não têm cessado de criticar as abordagens autoconsideradas neutras (Fernandes, 1980; Mills, 1965; Thiollent, 1981, 1985; Brandão, 1981; Freire, 1981), por sua inadequação frente à complexidade do objeto do qual se ocupam:

“...afirmar que uma sociologia não controvertida e livre de valores possa se desenvolver numa estrutura social baseada em conflito é teoricamente insustentável, praticamente irreal e moralmente desastroso" (Coulson \& Ridell, 1977; pg. 127).

Thiollent (1981) vai mais longe ao também sintetizar que
"O modelo de investigação que prevalece até hoje não pode ser imposto como único padrão de legitimidade científica. A pesar de sua ilusão de neutralidade, este modelo é requerido pela funcionalidade do saber em relação ao poder; neste sentido, ele é politicamente 'engajado'. É possível imaginarmos outro modelo de investigação que seja associado a uma política orientada em direção à emancipação e nem por isso menos 'científica' que o modelo convencional ligado ao poder vigente" (pg. 131).

Nas ciências do Homem, não cabe, como nos estudos positivos ou funcionalistas, sequer o propósito de "neutralidade, que é utópica, pois separa, drástica e artificialmente, meios de fins", mas no rumo de uma "busca de objetividade" (Camargo, 1978; pg. 295), entendida como racionalidade.

Nunes (1978), inclusive, ao referir-se à versão qualitativa da pesquisa sociológica, valoriza a explicitação das "relações interpessoais e sentimentais" entre pesquisador e pesquisado, as quais não constam nos manuais, mas que considera essenciais.

Frente a essa perspectiva, este trabalho deve incluir-se na linha da chamada sociologia crítica, onde Thiollent (1981, 1985), citando Habermas, como um dos expoentes dessa vertente, propõe substituir a observação pelo questionamento como eixo metodológico: "A noção de questionamento é muito mais adequada do que a de observação quando se trata de sociologia não-positiva".

Esta poderia ser uma forma de romper tanto com o chamado empiricismo quanto com o teoricismo - a grande preocupação de Thiollent. Tais questionamentos devem ser percebidos como uma

"comunicação na qual o sujeito que compreende deve introduzir os elementos de sua subjetividade que sejam de algum modo controláveis para encontrar o seu parceiro no terreno intersubjetivo de uma possível compreensão" (Thiollent, 1981 apud Habermas; pg. 23).

Dentre outros, Gouldner (Thiollent, 1981) também propõe ao pesquisador que ele se questione enquanto tal, individual, social e politicamente falando. 
Esta questão acaba sempre permeando todo o trabalho, porém exige que, pelo menos do ponto de vista individual, seja localizada a direção da busca.

\section{O QUESTIONAMENTO PESSOAL}

$\mathrm{Na}$ pesquisa em questão, pode se considerar que tanto objeto como objetivos não são dados ao acaso. Fazem parte de uma visão de mundo que se exprime numa prática e, acima de tudo, numa esperança em um devir não como utopia estéril nem como progresso, mas como possibilidade.

“A possibilidade não é a realidade, mas é também ela uma realidade: que o homem possa ou não possa fazer determinada coisa, isto tem importância na valorização daquilo que realmente faz. Possibilidade quer dizer 'liberdade' (...). Mas a existência das condições objetivas - ou possibilidade, ou liberdade - ainda não é suficiente: é necessário 'conhecê-las'e saber utilizá las. Querer utilizá-las. 0 homem, nesse sentido, é vontade concreta; isto é, aplicação efetiva do querer abstrato ou do impulso vital aos meios concretos que realizam essa vontade" (Gramsci, 1978; pg. 47).

Baseia-se, portanto, na visão de que a história se constrói através de sujeitos, dos agentes; enfim, daqueles aos quais é dado o poder de "re-flexão" e "re-formulação", tornando essencial o desejo - não enquanto pulsão atuando na esfera do id, mas como algo a conquistar, traduzido na integralidade, liberdade e superioridade de um Homem-Sujeito, onde a dominação, enquanto elemento nuclear das relações sociais, possa ser questionada para ser rompida.

Ou seja, o desejo de que essa possibilidade torne-se realidade precisa, necessariamente, estar por trás do desenvolvimento das análises que sustentam as práticas que possam concretizar tal "utopia". Utopia necessária enquanto um querer, e não como objetivo a ser alcançado a qualquer preço, e em que, numa relação dialética com as condições reais, possa pavimentar o caminho da concretização de uma nova realidade comprometida com a mudança em direção à liberdade.
É preciso superar, a curto prazo, os projetos de humanidade, permeados de novas, conscientes e totalizantes relações de dominação. Ou, ainda, as análises deterministas em que os suportes humanos encontram-se encalacrados, já que tudo "está escrito", restando apenas decorar o script e desempenhar, satisfatoriamente, o papel (Lefort, 1983; Fausto, 1983).

Da mesma maneira que as visões funcionais e de tipo ideal não satisfazem essa utopia, também aquelas decorrentes de uma certa leitura marxista definidora de papéis não dão conta das inquietações.

“Buscar um ator que pudesse personificar 0 projeto - um homem, um partido, uma teoria ou mesmo uma classe - seria ainda desconhecer as exigências criadas pelo desenvolvimento sócio-histórico, pela ampliação e aprofundamento agora exigidos de qualquer atividade revolucionária. 0 projeto revolucionário tornou-se de tal ordem que ele não terá nem sentido nem realidade se a esmagadora maioria dos homens e das mulheres que vivem na sociedade contemporânea não chegar a assumí-lo e a fazer dele a expressão ativa das suas necessidades e dos seus desejos. Não há salvador supremo, e nenhuma categoria particular tem a seu encargo destino da Humanidade" (Castoriadis, 1985; pg. 77).

Afinal, a dialética materialista não termina na mudança nacional de um regime ou na ditadura do proletariado.

Entendido o posicionamento que fundamenta a não-neutralidade, coloca-se novamente $o$ problema do método.

\section{A PESQUISA-AÇÃO E O PROBLEMA DA OBJETIVIDADE}

Quando iniciei o meu trabalho na saúde, participando também junto ao Movimento Popular, a quantidade de questionamentos que me invadia era tamanha, e tantas vezes limitando minhas intervenções, que, de pronto, sonhei em poder um dia iniciar um projeto de compreensão desse processo. Assim, quase que por intuição, comecei a guardar não só alguns documentos, mas, principalmente, depoimentos 
que sintetizavam posicionamentos característicos, com relatos em diário de alguns acontecimentos significativos. Logo em seguida surgiu a oportunidade de desenvolver o estudo da avaliação da experiência de Campinas (Possas, 1985), quando, tendo optado por pesquisar este tema, passei a aproveitar e recolher todo o material produzido relativo a ele. Pode-se, então, considerar que o procedimento metodológico utilizado a priori foi, desde logo, a observação participante, na qualidade de "participante completo". Mac Call \& Simmons (1969) caracterizam-no como aquele "que se adequa ou é a melhor forma de intervenção para informações do tipo "incidentes históricos'".

Aqui, a tentativa de controle da objetividade ou dos vieses se faz através da consciência de sua inviabilidade e da exposição das subjetividades.

Assim, embora haja quase unanimidade entre os autores em que a opção pela observação participante, como instrumento técnico de coleta de dados, seja a mais adequada para o objeto em questão, não quer dizer que a forma de sistematizar os seus resultados seja examinada sem discordância.

A discussão maior se dá em relação à questão da objetividade, onde aquilo que para alguns é fator gerador de bias, limitando o seu uso (Mac Call \& Simmons, 1969), para outros (Brandão, 1981; Fernandes, 1980; Freire, 1981; Thiollent, 1981, 1985) pode, dependendo da seriedade com que é abordado, tratar-se de compromisso ético-político. Para Fernandes (1981), por exemplo, o controle de qualidade reside em sua capacidade de "descrever e explicar os fenômenos", referindo-se à impossível separação entre observador e observado.

Thiollent (1981) inclusive sugere que:

“... em lugar de ser mera questão subjetiva, a dimensão polêmica das informações sociais deve ser considerada como reveladora de uma estrutura de relevância a ser objeto de preocupação metodológica por parte do investigador" (pg. 104).

Outros, ainda, assumem o resultado, interpretado dentro de suas características próprias, como uma das representações possíveis e presentes no imaginário. Nessa perspectiva, não haveria a realidade enquanto dado palpável e localizável positivamente, mas enquanto relação de dupla origem: na aparência e na representação. É um sentido que capta o objeto como algo que não pode ser "completamente determinado nem determinável", dado que não é, e nem se quer que seja, dominável: "O objeto completamente determinado, isto é, a objetividade, é o objeto completamente dominável, tanto ao nível do saber quanto ao nível da ação" (Chauí, 1981; pg. 35).

Concordando com os últimos, foi assumida a "perspectiva de objetividade", segundo autores afinados com a Teoria Crítica (Escola de Frankfurt), no questionamento e na busca intersubjetiva dos destinatários do diálogo, onde não há "conclusões reais" ou " verdades conclusivas" (Thiollent apud Habermas, 1981; De Decca, 1986; Chauí, 1981; Castoriadis, 1985; Lefort, 1974).

Levando em conta tais pressupostos, a pesquisa de campo foi feita com base na observação participante próxima à definida por Brandão (1981), em que:

“... a participação não envolve uma atitude do cientista para conhecer a cultura que pesquisa. Ela determina um compromisso que subordina o próprio projeto científico de pesquisa ao projeto político dos grupos populares cuja situação de classe, cultura ou história se quer conhecer, porque se quer agir" (pg. 12).

A possibilidade da "tensão permanente entre o risco de identificação total e a necessidade de uma tomada de distância a permitir o olhar crítico" (Doimo, 1981) foi viabilizada pelo espaço de tempo dado entre o período observado e vivido e o da sua descrição, dentro de uma linha qualitativa de pesquisa que se preocupa com as relações entre pesquisador e pesquisado, tendo em vista que, nesta, os dois elementos, até certo ponto, se confundiam.

Assim, fazendo a ressalva de que o que se recupera não é a realidade concreta, mas uma certa realidade, Freire (1981) é lembrado quando afirma que: “... ela é algo mais do que fatos e dados tomados em si mesmo (...), ela se dá na relação dialética entre objetividade e subjetividade" (pg. 35).

Nesta dimensão, Borda (1981) propõe os 
princípios metodológicos para a pesquisa participante:

- Não encobrimento das origens do observador;

- Preocupação em não "construir ciência para o povo";

- Restituição sistemática através de continuidade de trabalho conjunto;

- Respeito à cultura do outro.

Porém, o conhecimento próprio, adquirido das mais diversas formas, precisa ser considerado, seguindo um percurso que se aproxima da chamada pesquisa-ação (Thiollent, 1985).

Para maior rigor na observação dentro da investigação em questão, foi considerado não só o compromisso exigido na pesquisa participante, como também foram aproveitados os itens propostos em Asti Vera (1974), citando Selltz, Yahoda, Deutsch e Cook, ao levar em conta: “... os participantes, 0 ambiente, o propósito, 0 comportamento social e a duração dos fatos".

Por outro lado, quando muitas entrevistas e documentos relevantes são tomados em sua origem de discursos elaborados por vários elementos do movimento, como obras dos agentes sociais trabalhadores, isto também não se faz ao acaso, mas segundo o enfoque proposto por Trentin (1981), numa perspectiva gramsciana do processo de constituição das classes sociais,

“... buscando uma forma de favorecer a construção de um processo de conhecimento onde se exprime a autonomia cultural dos trabalhadores (...) a qual não é delegada aos especialistas da pesquisa" (pg. 261).

\section{Como Freire (1981) também aponta,}

“Dizer que a participação direta, a ingerência dos grupos populares no processo de pesquisa, altera a pureza dos resultados implica a defesa da redução daqueles grupos a puros objetos da ação pesquisadora de que, em conseqüência, os únicos sujeitos são os pesquisadores profissionais. $\mathrm{Na}$ perspectiva libertadora (...), a pesquisa tem como sujeitos cognoscentes, de um lado, os pesquisadores e, de outro, os grupos populares, e como objeto, a realidade concreta" (pg. $35)$.
Ainda com relação à pesquisa documental, o caminho sugerido por Chauí \& Franco (1978) propõe rigor ao considerar "... mais enriquecedor não tomar como critério a adequação entre 0 texto e o real, mas a representação do real veiculada pelo texto" (pg. 35).

\section{DE VOLTA ÀS TEORIAS}

A coleta de dados para a reconstituição do caso expõe elementos que passam a exigir uma pesquisa teórica obviamente necessária, no sentido de iluminar a compreensão das relações envolvidas. Ou seja, não bastam os testemunhos individuais, mas também saber a quantas andam as discussões teóricas a respeito dos temas em pauta (Fernandes, 1980).

No caso, foram então objeto de pesquisa teórica os estudos que tratam das relações entre o Estado e a Sociedade, sobretudo com referência aos países periféricos, tomando conhecimento dos mecanismos já descritos que analisam o processo pelo qual as categorias dirigentes, ou suas frações, operam nas diversas conjunturas para manter seus interesses. E, nessa ótica, entender como os autores dimensionam a política do welfare, onde se inclui a política de saúde.

Da mesma forma, tornou-se necessária a compreensão de como os teóricos da sociologia têm captado a questão do Movimento Social/ Movimento Popular, já que a vivência do caso sugeriu algumas peculiaridades.

\section{CONSIDERAÇÕES FINAIS}

A descrição e análise de experiências de articulação entre agentes de assistência à saúde e a população são fundamentais para a definição de projetos que efetivamente encontrem resposta junto à sociedade, tanto na qualificação do serviço em si quanto com relação ao aspecto pedagógico.

Projetos de atuação em saúde, sejam quais forem, sempre estabelecem relações dialógicas tanto com estruturas institucionais de maior poder na sociedade atual quanto com as de maior fragilidade (Offe, 1984; Jacobi, 1986; Smeke, 1989). 
O sentido de saúde, entendida como direito de cidadania, é algo a ser conquistado com muito maior amplitude (L'Abbate, 1990). E, nisto, nós - técnicos, pesquisadores, dirigentes - temos um espaço estratégico, essencial, que precisa ser melhor compreendido para ser melhor ocupado (Guiducci, 1979).

O desenvolvimento de investigações que procuram o percurso apontado oferece, com o necessário rigor, a possibilidade de se evidenciar mecanismos internos e imediatos que contribuem para uma melhor compreensão das relações existentes ou não entre determinações analisadas do ponto de vista macroestrutural e associações causais no plano microestrutural, bem como entre estrutura e superestrutura. Conhecê-los, debatê-los, parece fundamental para que novos projetos e propostas possam favorecer a ampliação de patamares mais elevados de vida e saúde para todos.

\section{RESUMO}

\section{SMEKE, E. L. M. Descobrindo Percursos para a Pesquisa em Saúde no Trato com 0 M ovimento Social. Cad. Saúde Públ., Rio de} Janeiro, 9 (1): 39-47, jan/mar, 1993.

O presente artigo trata da metodologia de trabalhos científicos em saúde nos quais o pesquisador é parte importante do objeto de investigação.

A concretização de uma reforma sanitária neste país depende do envolvimento e compromisso dos usuários na garantia dos seus direitos. Muitas experiências com essa preocupação vêm acontecendo no Brasil. Entretanto, não há uma metodologia pre-definida que trate das relações entre trabalhos institucionais em saúde e o Movimento Social.

Assim, o trabalho tem por objetivo contribuir para a discussão de possíveis caminhos para a abordagem dos mecanismos internos envolvidos nas relações saúde/usuários, com vistas a colaborar com o processo de desenvolvimento de cidadanias.

Ele se realiza a partir de uma pesquisa teórica sobre metodologia participante e pesquisa-ação, em que tomam importância: a definição do caráter do objeto; o posicionamento pessoal; a explicitação de subjetividades; levantamento documental e entrevistas para um estudo de caso; e retorno às teorias.

Finalmente, conclui-se que esta metodologia permite compreender alguns mecanismos que explicam as relações entre análises macro e microestruturais, além do amadurecimento dos agentes de pesquisa.

Palavras-Chave: Educação em Saúde; Participação Popular em Saúde; Movimento Social e Saúde; Pesquisa Social em Saúde

\section{REFERÊNCIAS BIBLIOGRÁFICAS}

AGUIAR, N., 1978. Observação participante e survey - uma experiência de conjugação. In: A A ventura Sociológica - Objetividade, Paixão, Improviso e Método na Pesquisa Social (E. O. Nunes, org.), pp. 125-151, Rio de Janeiro: Zahar.

ANDRADE, R. C., 1980. Política Social e normalização institucional no Brasil. In: A mérica Latina: Novas Estratégias de Dominação, (L. Maira; J. C. Portantiero; H. J. Souza; R. C. Andrade \& X. Barraza, orgs.), pp. 87-114, Petrópolis: Vozes/ Ce-dec.

ASTI VERA, A., 1974. Metodologia da Pesquisa Científica. Porto Alegre: Globo.

BOBBIO, N., 1982. O Conceito de Sociedade Civil. Rio de Janeiro: Graal.

BORDA, O. F., 1981. Aspectos teóricos da pesquisa participante. In: Pesquisa Participante (C. R. Brandão, org.), pp. 42-62, São Paulo: Brasiliense.

BOSCHI, R., 1982. Movimentos Associativos no Brasil Urbano. Rio de Janeiro: Zahar.

BRANDÃO, C. R. (Org.), 1982. Pesquisa Participante. São Paulo: Brasiliense.

CAMARGO, A. A., 1978. O ator, o pesquisador e a História, impasses metodológicos na implantação do CPDOC. In: A A ventura Sociológica Objetividade, Paixão, Improviso e Método na Pesquisa Social (E. O. Nunes, org.), pp. 276304, Rio de Janeiro: Zahar.

CARDOSO, F. H. \& FALETTO, E., 1973. Dependência e Desenvolvimento na A mérica Latina Ensaio de Interpretação Sociológica. Rio de Janeiro: Zahar.

CASTORIADIS, C., 1985. A Experiência do M ovimento Operário. São Paulo: Brasiliense.

CHAUÍ, M. S., 1981. Cultura e Democracia - 0 discurso competente e outras falas. São Paulo: Moderna. 
CHAUÍ, M. S. \& FRANCO, M. S. C., 1978. Ideologia e Mobilização Popular. Rio de Janeiro: Cedec/Paz e Terra.

COULSON, M. A. \& RIDELL, D. S., 1977. Introdução e Crítica à Sociologia. $3^{\circ}$ ed., Rio de Janeiro: Zahar.

DE DECCA, E., 1986. O Silêncio dos Vencidos. $3^{\circ}$ ed., São Paulo: Brasiliense.

DOIMO, A., 1981. Movimento Social Urbano e Igreja. Tese de Mestrado, Campinas: Faculdade de Antropologia, Universidade Estadual de Campinas.

FAUSTO, R., 1983. Marx: Lógica e Política. Vol. 1, São Paulo: Brasiliense.

FERNANDES, F., 1947. O problema do método na investigação sociológica. Sociologia, 9: 332-345. 1980. Fundamentos Empíricos da Investigação Sociológica. $4^{\circ}$ ed., São Paulo: T. A. Queiroz.

FREIRE, P., 1981. Criando métodos de pesquisa alternativa. In: Pesquisa Participante (R. R. Brandão, org.), pp. 34-41, São Paulo: Brasiliense.

GRAMSCI, A., 1977. A ntologia. Madrid: Siglo XXI. , 1978. Concepção Dialética da História. $2^{\circ}$ ed., Rio de Janeiro: Graal.

GUIDUCCI, R., 1979. A cidade dos cidadãos e a sociedade dos socialistas. In: 0 M arxismo e 0 Estado (N. Bobbio, org.), pp. 69-78, Rio de Janeiro: Graal.

HIRSH, J., 1977. Observações teóricas sobre o Estado burguês e sua crise. In: 0 Estado em Crise, (N. Poulantzas, org.), pp. 103-132, Rio de Janeiro: Graal.

JACOBI, P., 1986. Políticas Públicas de Saneamento Básico e Saúde e Reivindicações Sociais no Muni-cí-pio de São Paulo, 1974-1984. Tese de Doutorado, São Paulo: Faculdade de Filosofia, Letras e Ciências Humanas, Universidade de São Paulo.

JACOBI, P. \& NUNES, E.O., 1982. Movimentos urbanos, poder local e conquista da democracia. In: Cidade, Povo e Poder (J. A. Moises, org.), pp. 165-199, Rio de Janeiro: Cedec/Paz e Terra.

L'ABBATE, S., 1990. 0 Direito à Saúde: da Reivindicação à Realização - Projetos de Políticas de Saúde em Campinas. Tese de Doutorado, São Paulo: Faculdade de Filosofia, Letras e Ciências Humanas, Universidade de São Paulo.
LEFORT, C., 1974. Esboço de uma gênese da ideologia nas sociedades modernas. Estudos do CEBRA P, 10: 7-55.

, 1983. A Invenção Democrática - os

Limites do Totalitarismo. São Paulo: Brasiliense.

MAC CALL, G. \& SIMMONS, J. L., 1969. Issues in Participant Observation. N. York: Addison-Wesley Publishing Company.

MILLS, C. W., 1965. A Imaginação Sociológica. Rio de Janeiro: Zahar.

NUNES, E. O., 1978. Introdução à Aventura Sociológica. In: A A ventura Sociológica - Objetividade, Paixão, Improviso e Método na Pesquisa Social (E. O. Nunes, org.), pp. 9-18, Rio de Janeiro: Zahar.

OFFE, C., 1984. Problemas Estruturais do Estado Capitalista. Rio de Janeiro: Tempo Brasileiro.

POSSAS, C. A., 1985. Campinas, uma experiência em Saúde. (Relatório final do projeto de avaliação permanente de Saúde em Campinas), Rio de Janeiro: FINEP/PUCCAMP. (Mimeo.)

POULANTZAS, N., 1977. O Estado em Crise. Rio de Janeiro: Graal. , 1978. As Classes Sociais no Capitalismo Hoje. $2^{\circ}$ ed., Rio de Janeiro: Zahar. , 1985. O Estado, o Poder e o Socialismo. $2^{\circ}$ ed., Rio de Janeiro: Graal.

SMEKE, E. L. M., 1989. Saúde e Democracia Experiência de Gestão Popular: um Estudo de Caso. Tese de Doutorado, Campinas: Faculdade de Ciências Médicas, Universidade Estadual de Campinas.

TEIXEIRA, S. M. F., 1986. Cidadania, Direitos Sociais e Estado. Brasilia, VIII Conferência Nacional de Saúde. (Mimeo.)

THIOLLENT, M., 1981. Crítica Metodológica, Investigação Social \& Enquete Operária. $2^{\circ}$ ed., São Paulo: Polis. 1985. M etodologia da Pesquisa- A ção. São Paulo: Cortez/Autores Associados.

TRENTIN, B., 1981. Pesquisa sobre consciência de classe. In: Crítica M etodológica, Investigação Social \& Enquete Operária (M. Thiollent, org.), $2^{\circ}$ ed., pp. 257-262, São Paulo: Polis. 